\title{
MicroRNAs in Pancreatic Cancer: biomarkers, prognostic, and therapeutic modulators
}

\author{
Afra Z. Daoud ${ }^{1 \dagger}$, Eoghan J. Mulholland ${ }^{2 \dagger}$, Grace Cole $^{3,4}$ and Helen O. McCarthy ${ }^{1 *}$ (iD
}

\begin{abstract}
A severe lack of early diagnosis coupled with resistance to most available therapeutic options renders pancreatic cancer as a major clinical concern. The limited efficacy of current treatments necessitates the development of novel therapeutic strategies that are based on an understanding of the molecular mechanisms involved in pancreatic cancer progression. MicroRNAs (miRNAs) are non-coding small RNAs that regulate the expression of multiple proteins in the post-translation process and thus have promise as biomarkers, prognostic agents, and as advanced pancreatic therapies.

Profiling of deregulated miRNAs in pancreatic cancer can correlate to diagnosis, indicate optimal treatment and predict response to therapy. Furthermore, understanding the main effector genes in pancreatic cancer along with downstream pathways can identify possible miRNAs as therapeutic candidates. Additionally, obstacles to the translation of miRNAs into the clinic are also considered.

Distinct miRNA expression profiles can correlate to stages of malignant pancreatic disease, and hold potential as biomarkers, prognostic markers and clinical targets. However, a limited understanding and validation of the specific role of such miRNAs stunts clinical application. Target prediction using algorithms provides a wide range of possible targets, but these miRNAs still require validation through pre-clinical studies to determine the knock-on genetic effects.
\end{abstract}

Keywords: Pancreatic Cancer, microRNA, Biomarker, Prognosis, Chemoresistance, Gene therapy

\section{Background}

\section{Introduction to Pancreatic Cancer}

Cancer is a devastating disease, and of the 18 million diagnosed globally in 2018, approximately 500,000 cases were pancreatic [1]. Furthermore, pancreatic cancer (PC), in all forms, has the lowest survival rate of any cancer type; with less than $1 \%$ overall 10 -year survival, and 3\% overall 5-year survival based on statistics of patients from England and Wales [2]. Although significant progress has been made in the development of novel cancer therapies, PC survival rates have failed to improve in the last 40 years [2]. A fundamental reason for this is that PC typically presents as an advanced disease

\footnotetext{
* Correspondence: h.mccarthy@qub.ac.uk

${ }^{\dagger}$ Afra Z. Daoud and Eoghan J. Mulholland contributed equally to this work. 'School of Pharmacy, Queen's University Belfast, 97 Lisburn Road, Northern Ireland BT9 7BL, UK

Full list of author information is available at the end of the article
}

with extensive metastatic deposits that arise in the liver [3]. Additionally, surgeons are often reluctant to conduct resections on local tumours due to growth around vital arteries and para-aortal metastases $[4,5]$.

The evolution of genetic mutations required for metastasis can take over a decade to come into fruition from the initial primary non-metastatic cell within the pancreas [3]. This means that if the disease is detected within the first couple of years of tumorigenesis, there is a significantly improved chance of disease control with effective treatment [6]. Abdominal pain and abnormal digestive patterns have been reported to be recurring in $70 \%$ patients with PC diagnosis, which in later stages become more apparent with specific patterns identified [7].

Diabetes mellitus (DM) is unsurprisingly found in two thirds of PC patients. Studies consistently show an increase in the risk of PC development with type $2 \mathrm{DM}$ [8]. Furthermore, in a recent study by Wang et al. [9], 
DM was linked with increased metastasis in PC patients. These findings were linked to an increased inflammatory response accompanied by high glucose levels promoting PC progression [9]. Nonetheless, the pancreatic tumour itself can be diabetogenic resulting in dysfunctional $\beta$ cells, required for insulin production [10]. This explains the association of PC with $10 \%$ of new-onset diabetes [11], as well as highlighting newly developed DM as a possible PC symptom.

Taken together, these facts indicate that PC is still a challenge in terms of diagnosis, treatment and prognostic outlook. This review therefore will explore the molecular changes which can occur in PC development and progression, and how (microRNA) miRNA can play a role in terms of, disease screening, prognoses and new therapeutic options.

\section{Main text}

Molecular changes during Pancreatic carcinogenesis

The development of PC is a multistage process that involves alterations in well-characterised genes [12]. One of the most commonly mutated oncogenes is the Kirsten Rat Sarcoma (K-RAS) gene, detected in $90 \%$ of PC cases [11].

Typical PC tumour suppressor mutations can be found in cyclin-dependent kinase (CDKN2A), tumour protein 53 (TP53), mothers against decapentaplegic homolog 3 (SMAD3), and breast cancer A2 (BRCA2) [13]. These genetic mutations result in histological and morphological abnormalities within the ductal cells of the pancreas, forming papillary-like structures. These papillary lesions then transform into more complicated preneoplastic lesions known as pancreatic intraepithelial neoplasia (PanIN) [14]. The formation and development of PanINs occur in a stepwise linear manner that is concurrent with the aforementioned genetic mutations. As a result, more complicated structures develop, progressing to the invasive (carcinoma) tumour cells (Fig. 1). Thus, PanINs are classified based upon cellular morphology, as PanIN-1A, $-1 \mathrm{~B},-2$ or -3 . PanIN-1A and PanIN-1B are more elongated compared to the normal ductal cells and cells with flat structures fall under the PanIN-1A subgroup. Both A and B subgroups are linked by the early mutation of the K-RAS oncogene. With the inactivation mutation of CDKN2A, the lesions progress and acquire moderate nuclear abnormality, forming PanIN-2. Ultimately, nuclear atypia ensues with the budding of cells into the ductal-like structure in the late lesions known as PanIN-3. These late lesions arise as a result of inhibitory mutations of p-16 and SMAD-4 and are also dubbed as in situ carcinoma [15]. PanINs can also be divided into low-grade or high-grade, with a high rate of occurrence of low-

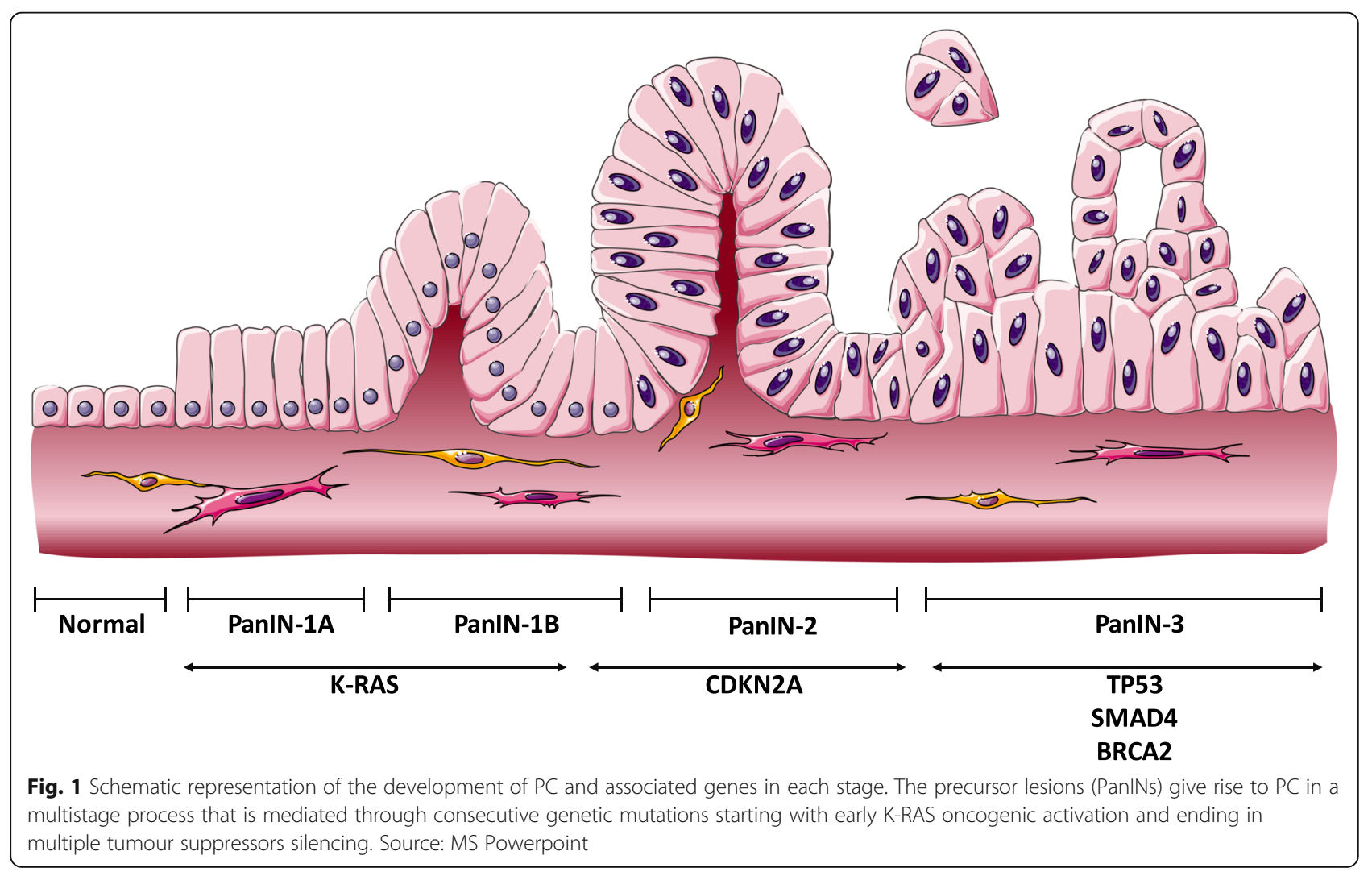


grade in the early stages of PC and excessive tumour invasion happening in the later stages [16].

\section{Oncogene activation}

K-RAS is a member of the Ras family, a guanosine triphosphate (GTP) family of bound proteins. Active Ras proteins bind to GTP and are responsible for proliferation, cell survival and cytoskeletal remodelling through the regulation of several downstream modulators. The activity of Ras is then terminated through the hydrolysis of GTP into guanosine diphosphate (GDP), mediated by GTPase activating protein (GAP) [17].

Mutations arise in the K-RAS oncogene in glycine 12 (G12), glycine (G13), or glutamine (Q61L) resulting in sustained K-RAS activity through maintaining the GTPbound active form of the protein [18]. This results in persistent activation of the downstream signalling pathways, which will be translated in a typical cancerous cell phenotype including aberrant proliferation, microenvironment alterations, apoptosis suppression and cell survival.

To study the impact of mutated K-RAS on tumour progression, Collins et al. [19] engineered two mouse models to have reversibly inducible K-RAS mutation that is tissue-specific. The two models are iK-Ras* and iK-Ras-p53 ${ }^{+/}$, in which the latter has an extra inactivation mutation of one allele of the p53 gene. These mouse models are believed to develop pancreatic lesions in a manner mimicking human disease, with PanINs developed within three weeks of K-RAS mutation induction in the iK-Ras* model. This model was used to demonstrate the key role of K-RAS in the initiation of the tumours. On the other hand, inactivation of K-RAS mutation in the iK-Ras-p53 ${ }^{+/-}$model resulted in tumour regression. The same response was noted by other authors using the iK-Ras mouse model [20]. They have recorded rapid tumour and stromal deterioration upon turning the K-RAS mutation off, with $50 \%$ reduction in tumour mass after $48-72 \mathrm{~h}$ of K-RAS genetic inhibition [20]. These findings elucidate the importance of K-RAS in maintaining carcinogenesis irrespective of any additional mutations, in a phenomenon known as "K-RAS addiction" [21]. Oncogene addiction materialises when a cancer requires the sustained activation of a specific oncogene, even after the incorporation of additional genetic mutations through advanced stages [22]. This phenomenon doesn't repudiate the importance of additional mutations on tumour suppressor genes in the progression of tumours, as the tumours formed in the absence of other tumour suppressor mutations were stable with infrequent invasiveness [20, 23]. This does indicate that the K-RAS gene could be a potent therapeutic intervention in pancreatic cancer.
The two main downstream pathways of activated KRAS include mitogen-activated protein kinase (MAPK) [24] and phosphoinositide-3-kinase (PI3K) [25], which have significant roles in promoting cell survival and proliferation. MAPK is a superfamily of protein kinases, including subfamilies that are identified and characterised in mammalian cells: extracellular signal-regulated kinases (ERK1/ERK2), the c-Jun N-H2 terminal kinases/ stress-activated protein kinase (JNK/SAPK), and the P38 enzymes. Activation of the MAPK pathways is associated with poor prognosis in PC patients through the activation of several downstream pathways. Of these pathways, ERK1/2 [26] and P38 [27] are critical downstream modulators; however, the role of the P38 pathway is contradictory. As shown by Handa-Luca et al. who studied 99 surgically resected PC, increased cytoplasmic levels of P38 and ERK1/2 were linked with high recurrence after surgical resection of $\mathrm{PC}$, and lower overall survival rates of 7 months compared to 35 months for patients showing low cytoplasmic levels [28]. Interestingly, through the analysis of 36 rapid biopsies from patients, increased levels of P38 were linked with good prognosis. This was evident as the postoperative survival was noted, with a median survival rate of 27.9 months in patients showing high levels of P38 compared to 14.7 months in those with low P38 expression [29]. The samples from this study were taken from patients presenting with all types of PC, whereas the study conducted by Handa-Luca et al. contained only pancreatic ductal adenocarcinomas patient samples. This highlights the diversity in $\mathrm{PC}$ and how molecules can have multiple roles.

The progressive role of inflammatory stress accompanied with the tumour microenvironment is believed to be activated through the P38 pathway [30]. Huang et al. recorded increased proliferation and invasion of a PC cell line, PANC-1, upon targeting the $\beta$-adrenergic receptors with the stress hormone, norepinephrine (NE), which was accompanied by elevated levels of the active phosphorylated P38 [30]. Yet, Ding et al. demonstrated that upon the inhibition of P38 MAPK pathway, ERK1/2 phosphorylation increased, which translated to the enhancement of PANC-1 proliferation [31].

These findings indicate that the P38-MAPK pathway has a controversial role in the development of pancreatic cancer. This contradiction may be explained by the availability of four different P38 paralogues: P38 $\alpha$, P38 $\beta$, P38Y and P38 (reviewed in [32]) which should be further interrogated.

\section{Tumour suppressor gene mutations}

The CDKN2A gene encoding p16 is a tumour suppressor commonly inactivated in pancreatic cancer $(90 \%$ of the cases [33]). The CDKN2A gene encodes two families of tumour suppressor proteins. Out of these families, 
inhibitors of the CDK4 (INK4) family is denoted mainly by $\mathrm{p} 16$ and $\mathrm{p} 19$ which are located on the same locus. However, these proteins are not considered to be isoforms of each other since they are being translated from two separate messenger RNAs (mRNA) produced by CDKN2A [34]. The most abundant inactivation mutation is believed to happen uniquely on p16. Inactivation of p16 can occur via homozygous deletion, intragenic mutations or epigenetic silencing [33, 34], which results in cell cycle disruption through the G1/S checkpoint inhibition. This disruption will result in uncontrolled transcriptional activation which will contribute to a positive feedback loop, leading to increased cell division and proliferation [35].

Another mutated tumour suppressor gene is TP53 encoding for p53, a transcription factor that is activated by cellular stress [36]. DNA damage, radiation, aberrant growth signals and some chemotherapeutic agents will cause cellular stress, thus activating the p53 pathway [37]. P53 activation results in cell division, inhibition, or in the case of extremely damaged cells, death through apoptosis [36]. The p53 mutation was recorded in $70 \%$ of PC, which mainly presents as a loss of function [38]. However, these mutations can also provide oncogenic function, as p53 silencing has been shown to increase the expression of platelet-derived growth factor receptor $\mathrm{b}$ (PDGFRb) which correlates directly with invasiveness and metastasis $[39,40]$.

Both tumour suppressor proteins p16 and p53 bind and inactivate CDK2 and 4 which impacts the cell cycle by preventing transition from $\mathrm{G} 1$ to $\mathrm{S}$ phase [41, 42]. Any inactivation of these proteins will result in cell cycle progression despite the G1/S checkpoint status ensuring continuous proliferation [43].

Another tumour suppressor gene that is commonly deregulated in $\mathrm{PC}$ is the pancreatic carcinoma 4 gene (DPC4, also known as SMAD4), which is upregulated in $55 \%$ of PC [41]. Loss of SMAD4 facilitates a selective growth advantage, through the regulation of the transforming growth factor- $\beta$ (TGF- $\beta$ ) signalling pathway [42]. Upon activation of the TGF- $\beta$ pathway, an intracellular cascade takes place through activation of the cell surface serine-threonine kinase receptor type II (TßRII) which will cause activation of the type I receptor through phosphorylation of the glycine- and serine-rich sequence (GS) domain located on the N-terminal of the type I receptor [42]. Receptor-activated SMADs, called R-SMADs, form trimeric complexes composed of two RSMADs and an essential co-SMAD which is the SMAD4. These tri-complexes, translocate to the nucleus and target DNA to regulate specific genes that have anti-mitogenic and pro-apoptotic effects [41, 43]. The importance of SMAD4 in all TGF- $\beta$ pathways as an essential co-factor explains the cardinal effect of SMAD4 mutations on modulating most genetic responses to the TGF- $\beta$ superfamily.

Ultimately, cellular anaplasia and relapses, lymphatic invasion, postoperative recurrence, tumour size and metastasis to lymph nodes status have all been linked to mutations in p53, p16, and SMAD4 [44]. Thus, all of these genetic mutations offer great potential for gene therapy interventions. The utilisation of miRNA for the targeting of these mutations presents an opportunity to regulate multiple pathways with a single therapeutic [45].

\section{miRNAs}

MicroRNAs form a subfamily of non-coding RNAs which regulate gene expression via mRNA degradation or translatory inhibition [46]. Approximately 50\% of miRNAs are encoded on non-protein-coding regions and are independently transcribed. The remaining miRNAs are encoded on introns of protein-coding transcripts. In this case, miRNAs are referred to as intergenic miRNA and will be transcribed with host genes and processed separately to produce the mature independent miRNA [47]. The biogenesis of miRNAs is summarised in Fig. 2.

Activated miRNA is incorporated within the RNAinduced silencing complex (RISC), and this multipart will bind to the target mRNA, typically on a conserved site called the seed region. This region is included within the $3^{\prime}$ untranslated region (3'UTR) between nucleotide $2-8$, and functions as a target recognition site as the binding between the two strands has $100 \%$ complementarity [48]. Conserved seed matches are linked with more knockout potency as a single nucleotide change alters the possible targets by more than 50\% [49].

The cornerstone of miRNA binding is based on 3 rules: perfect or near-perfect complementary binding in the seed region, central region mismatches or "bulges" and the reasonable complementarity throughout the full sequence of the miRNA with the target. It is important to mention that complementarity through the two sequences is particularly significant in the case of suboptimal binding in the seed region. While the full sequence of the miRNA has possible base mismatches, these mismatches do not affect the functionality of the complex. In fact, it gives the miRNA more extensive mRNA target possibilities [48]. The importance of complementary binding in the seed region is explained by the fact that it is the cornerstone in target recognition. Furthermore, the bulges facilitate the binding and functionality of the Ago protein, an essential component of the RISC required for the assembly and guidance to target mRNAs [50]. Lastly, the manner of complementary binding throughout the miRNA and the target mRNA sequence will determine the inhibitory mechanism of the 


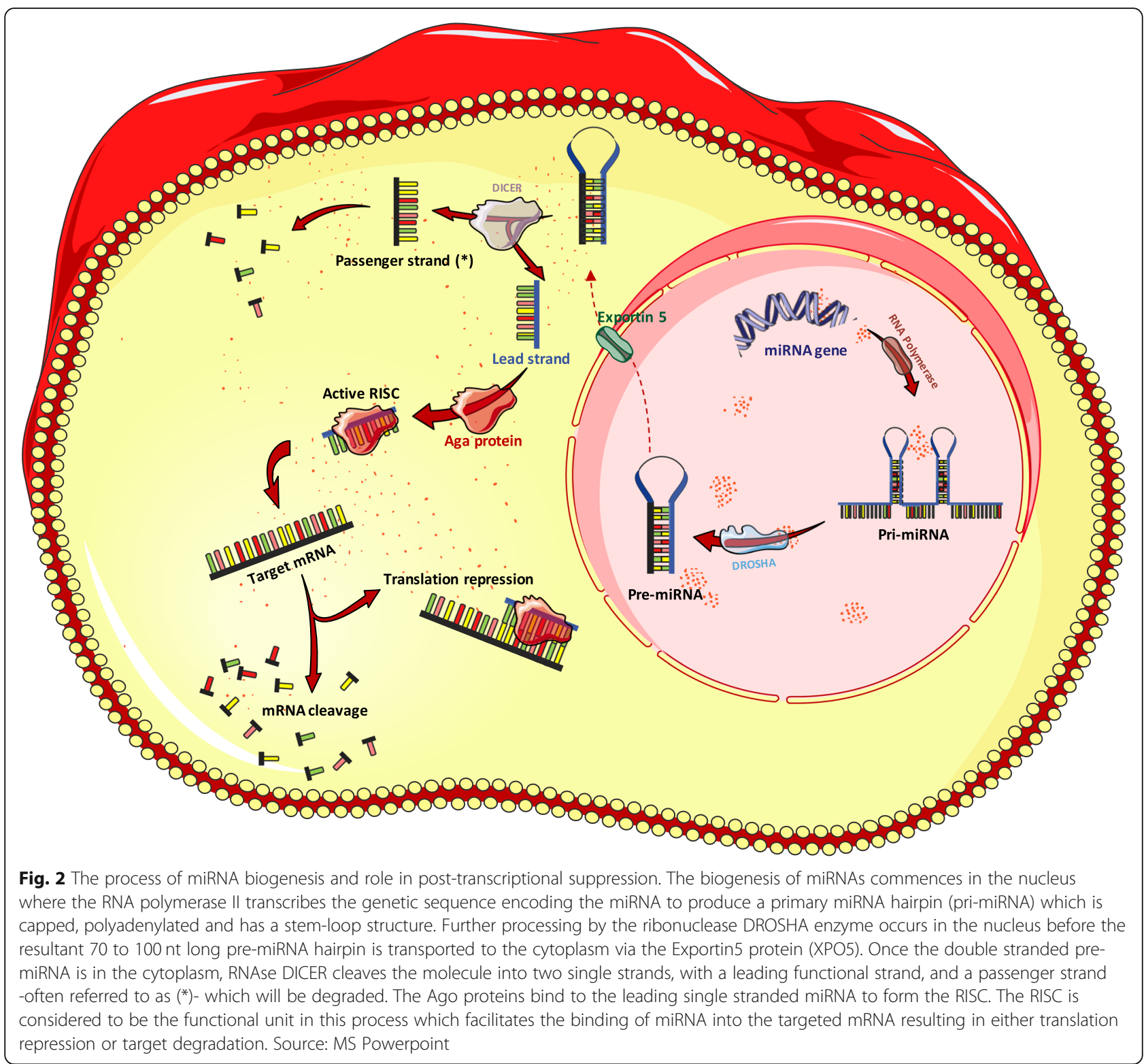

translation process. If the binding occurs in a perfect complementary fashion throughout the whole sequence, complete degradation of the target mRNA will take place [51]. On the other hand, if few base pair mismatches were present during the binding process, the translation blockade will ensue through destabilisation of the target mRNA by non-splicing mechanisms. These mechanisms include decapping or deadenylation which represents the most abundant mechanism of silencing $[48,52]$.

Exosomes are extracellular vesicles which are endosomal in basis and typically range in size between 40 and $100 \mathrm{~nm}$ and function to secrete and carry biological materials between cells [53]. MiRNA can also be secreted from cells within exosomes, and these 'exomiRNAs' have exhibited extensive evidence of influencing cancer initiation and development. For example, exosomal miRNA-301a was found to trigger the M2 polarisation of macrophages when derived from hypoxic pancreatic cancer cells which was attributed to the activation of the PTEN/PI3K $\gamma$ pathway [54]. Interestingly, studies have shown that exomiRNAs have the potential to be novel biomarkers collected from blood serum. Studies conducted by Pang et al. showed that pancreatic cancer cells produce and secrete miRNA155 within exosomes, with the function of activating fibroblasts [55]. Furthermore, exosomes are nonimmunogenic and protect biological cargo thus make for excellent gene therapy systems. However, major hurdles of getting exosomes into the clinic include the efficient loading of miRNA into exosomes, with 
influencing factors including solubility and charge. Furthermore, the pathways on which any therapeutic miRNA functions would need to be extensively defined, to avoid undesirable off-target effects [56].

\section{miRNA in Pancreatic Cancer}

miRNAs play a major role in carcinogenesis, falling into two categories: tumour suppressor miRNAs, and oncogenic miRNAs (also termed oncomiRs) [57]. The classification is dependent on the role of the target mRNAs in the tumour initiation process. Normally, oncogenes and tumour suppressor genes are regulated at an optimal activation/inhibition equilibrium. If downregulation of a specific miRNA increases the activity of a corresponding oncogene, this is identified as a tumour suppressor miRNA. On the other hand, if upregulation of an oncomiR takes place, it will result in a continuous inhibition of the target tumour suppressor gene. This uncontrolled inhibition will result in the loss of controlling specific tumour formation pathways. Deregulation in any of the miRNA types will contribute to the development of tumours [58].

Patterns of miRNA expression vary markedly between cancer types; thus, the use of miRNA expression profiles could be used as a promising non-invasive diagnostic markers. Furthermore, miRNA profiling should have superiority over using mRNA profiles as they can represent many more reliable targets [59]. Identification of a small number of miRNA has been shown to be more reliable than the data from 16,000 mRNAs with a more robust hierarchical clustering [59]. In pancreatic cancer, different patterns have been found in miRNA expression profiles, which have contributed to the development of a miRNANome between the normal and cancerous pancreas [60]. Determination of these miRNA expression profiles has been made possible through different gene profiling methods, mainly microarrays, RNA-sequencing, and RT-PCR analysis of specimens [61]. Due to the stability of miRNA in circulation, blood screening could be employed as an approach to detect specific miRNA which have been linked with stage, survival rate or aggressiveness of the disease [62-64].

Variations in the results observed among different studies are generally thought to be caused by ethnicity and regional differences [65]. Another important factor is the sampling procedure, as fine needle aspiration (FNA) results in enriched samples with a specific tumour component, disregarding other cell types during the microdissection process. This observation was illustrated by the molecular differences obtained from bulk samples compared to fine needle aspirations[66]. Comparing expression patterns among different samples could also allude to the abundance of miRNAs among different cell types that are naturally occurring in the pancreas, as well as the tumour microenvironment. For example, miRNA-375 was suggested to be linked with the islet cells [67], as the expression was high in normal pancreatic tissues compared to the cancerous and inflammatory tissues with a complete absence in representative cell lines [60].

miRNA samples can also be obtained via non-invasive routes from, peripheral blood, saliva, urine or faeces [68]. Abue et al. conducted a study to analyse the potential of miRNA-483-3p and miRNA-21 as biomarkers of pancreatic ductal adenocarcinoma from blood plasma. These plasma samples were obtained from 32 patients presenting with pancreatic ductal adenocarcinoma, 12 patients with intraductal papillary mucinous neoplasm, and 30 healthy control individuals. The levels of these miRNA were evaluated using qRT-PCR, compared between groups and the expression of each was linked clinically. The plasma expression of both miRNA-483-3p and miRNA-21 was found to be significantly higher in pancreatic ductal adenocarcinoma compared to healthy controls $(p<0.01)$. The plasma expression of miRNA483-3p was significantly higher compared to intraductal papillary mucinous neoplasm $(p<0.05)$, and the expression of miRNA-21 was linked to advanced stage disease $(p<0.05)$ with metastases in the lymph nodes and liver $(p<0.01)$. Indeed, miRNA expression correlated with an overall lessened survival in those patients with pancreatic ductal adenocarcinoma $(p<0.01)$ [69].

\section{miRNAs as biomarkers}

Identification of early biomarkers is essential in cases where PC surgical resection is the only curative treatment. Surgery is only feasible in $15-20 \%$ of patients who have been diagnosed with early stages of PC $[70,11]$. However, the postoperative complications associated with this surgery are frequent and cases such as chronic pancreatitis or pancreatic tuberculosis are usually hard to differentiate from cancer cases [71]. To date, the serum carbohydrate antigen 19-9 (CA 19-9) has been employed as a marker for assessing clinical treatment efficacy in pancreatic cancer [72]. Limitations associated with CA 19-9 include ineffectiveness, low sensitivity and low specificity, yet it is still the only FDA approved marker in PC. Other antigens such as CEA, and CA125 were completely ineffective as early markers, but some oncologists still use them as markers of therapy responsiveness [73]. Therefore, the PC diagnostic biomarker need could be met by utilising identified miRNAs as an early screening test [74]. Advantages of using miRNAs include stability in serum, ease of non-invasive detection in circulation and a convenient screening method [75]. 
Lee et al. used pancreatic cancer, paired benign pancreatic tissue, normal pancreas, and pancreatitis tissues along with nine cell lines to compare miRNA expression profiles [90]. This was achieved through employment of real-time PCR profiling of $>200$ miRNA precursors. The diversity of sample types used gives the study a broader spectrum of comparison and a chance of detecting the premalignant changes that occur through the conversion step from benign abnormalities to malignant tumours. Among the top aberrantly expressed miRNAs (Fold change, $P$-value) in cancer samples, miRNA-424 (56.3, 3.62E-08), miRNA-100 (36.9, 4.40E-06), miRNA-301 (34.2, 1.11E-05), miRNA-212 (22.2, 2.00E-04) and miRNA-125b-1 (23.2, 1.00E-04) were overexpressed, whereas miRNA- 345 (-14.5, 1.44E-15), miRNA-142-P (15.4, 3.63E-07), and miRNA-139 (- 7.91, 6.79E-11) were all downregulated, relative to normal pancreatic samples. Additionally, miRNA-221, miRNA-376a, and miRNA301 were found to be localised within the tumour cells rather than other cells in the stroma [76].

MiRNA-155 and miRNA-21 were also found to have elevated expression in the precursor lesions, linking them with histological progression features, with a specificity of miRNA-155 as a biomarker in pancreatic juices [77]. The top five upregulated miRNA included miRNA-21, miRNA-196a, miRNA-27a, miRNA-146a, and miRNA-200a as listed by Hong and Park [78] following fine needle aspiration (FNA). In comparison, the most downregulated miRNAs included miRNA-96, miRNA-217, miRNA-141, miRNA-20a, and miRNA29c [78]. Other upregulated candidates were demonstrated via qRT-PCR by Zhang et al,, and include miRNA-196a, miRNA-190, miRNA-186, miRNA221, miRNA-222, miRNA-200b, miRNA-15b, and miRNA-95, [79]. Further evidence also showed that miRNA-21, miRNA-26b, miRNA-194, miRNA-200b, miRNA-200c, miRNA-320, miRNA-374 and miRNA429 were upregulated in $\mathrm{PC}$ cell lines compared to normal pancreas cell lines [80].

Early stage K-RAS mutations, observed in PanIN lesions, can directly affect the levels of specific miRNAs as shown by the Cordelier group [67]. Upregulation of miRNA-205, miRNA-200, and miRNA-21 was detected in early adenocarcinoma lesions, through use of a KRAS(G12D) mouse model where miRNA production could be measured in pathological and nonpathologic ducts. The level of increased miRNA-21 expression was also proportional to the degree of morphological changes within the lesions [81], as quantified using qRT-PCR of PanIN samples using U6 as a housekeeper gene. The mechanism of action of miRNA-21 is summarised in Fig. 3. Upregulated miRNA-372, miRNA-146a, miRNA-204, miRNA-10a, and miRNA$10 \mathrm{~b}$ were also detected in PC cell lines (CAPAN-1 and
CFPAC1) compared to human normal pancreatic ductal epithelial cells, with more than 10-fold changes in the latter levels [82] observed using qRT-PCR.

A further study [60] showed distinct expression levels in normal pancreatic tissues. Candidate miRNAs: miRNA-141, miRNA-148a, miRNA-200a, miRNA-200b, miRNA-200c, miRNA-216, miRNA-217, and miRNA375 exhibited high expression levels in the normal pancreatic tissue compared with 33 other human tissues analysed in the same array. Alternatively, there were low expression levels with miRNA-133a, miRNA-143, miRNA-145, and miRNA-150 in cancerous tissue[60]. MiRNA-216 and miRNA-217 were found to have extensive infiltration in normal pancreatic tissues, and neglible levels in both cancerous tissue and pancreatic cell lines. The unique expression of these two miRNAs in normal pancreatic tissue samples compared to diseased tissues and cell lines renders a specificity for the pancreatic abundance. A global study also showed that both miRNA-216 and miRNA-217 were absent from 33 different human tissues [60]. MiRNA-93, miRNA-196a, miRNA-196b, miRNA-203, miRNA-205, miRNA-210, miRNA-221, miRNA-222 and miRNA-224 were upregulated only in cancerous tissues and cell lines. This observation is linked with a potential role in the neoplastic process. Special interest should be directed towards miRNA-196a and miRNA-196b as complete absence was observed in the normal and pancreatitis tissues. This gives a potential selectivity to pancreatic cancer as detailed in Table 1 [60].

\section{miRNAs as prognostic factors}

Profiling miRNAs among patient samples with different disease characteristics and stages gives an understanding of the prognostic role of miRNAs, many of which are listed in Table 2. It was shown in a retrospective clinical study comprising 200 pancreatic ductal adenocarcinoma tissue samples (Department of Hepatobiliary and Pancreas Surgery of Seoul National University Hospital) that in a high-risk group (median survival time $=17.2$ months) miRNA-574-5p, miRNA-1244, miRNA-4474-5p were upregulated. While miRNA-574-5p, miRNA-1244, miRNA-145-*, miRNA-328, miRNA-26b*, and miRNA4321 showed association with overall survival (OS) and disease-free survival (DFS) [83]. Taubert and coworkers [84] have investigated the role of miRNA-155, miRNA203, miRNA-210, miRNA-222, miRNA-216, and miRNA-217 in overall survival. Upregulation of the first four of this group showed a correlation with poor prognosis and overall survival, while the same effect has been noticed with the downregulation of miRNA-217. In terms of miRNA-216, no effect has been detected in either up or downregulation. Tumour-related death increased 5.24-fold when the overexpression of miRNA- 


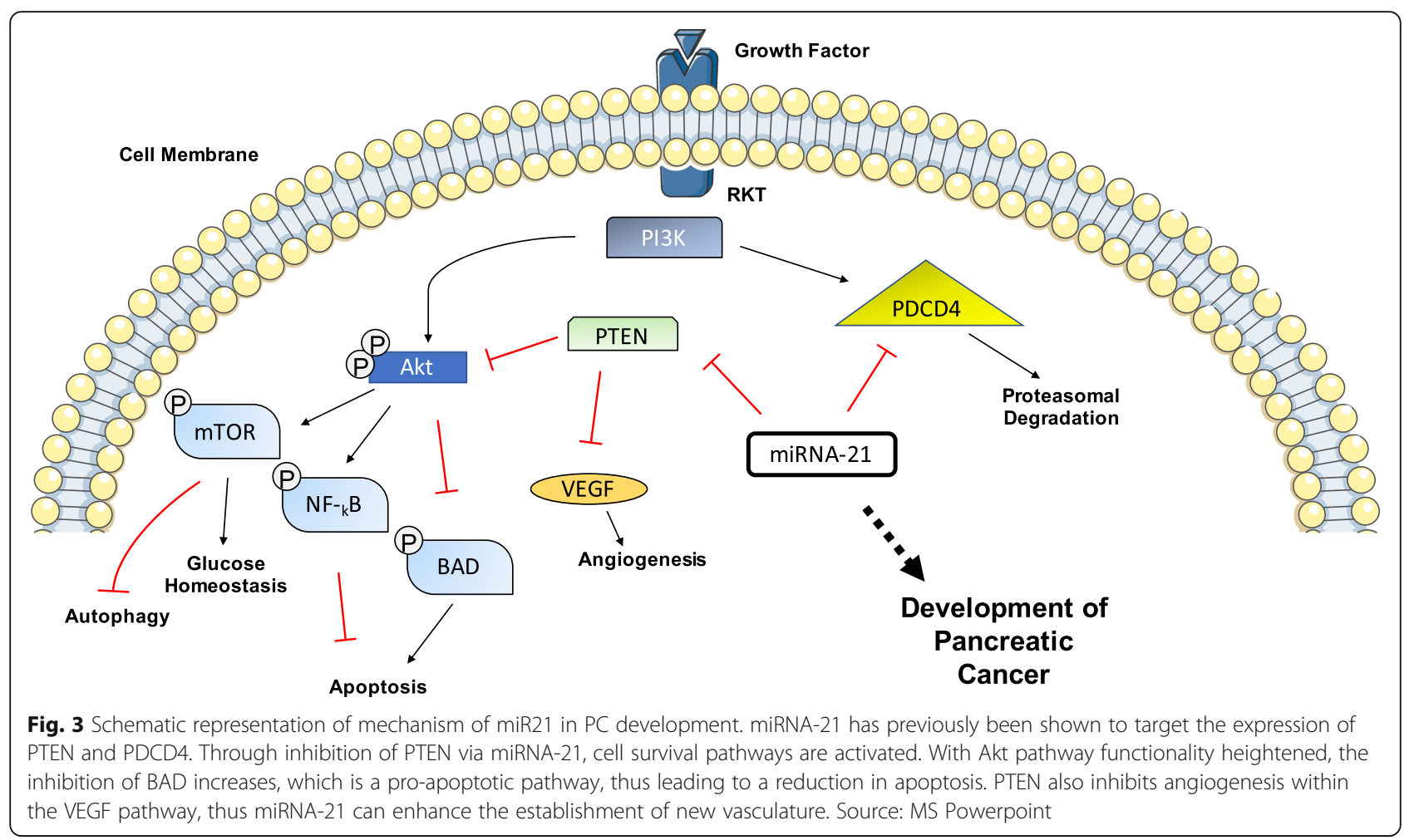

155, miRNA-203, miRNA-210, and miRNA-222 is combined [84]. miRNA-21 is also another indicator of poor outcome [85, 86]. Increased expression of miRNA-196a2 resulted in a lower survival time (median survival time $=14.3$ months) compared with downregulated expression (median survival time $=26.5$ months) $[86,87]$. Similar effects occurred with miRNA-219 as the median survival rate was 13.6 months in the overexpressing tumours, and 23.8 months in the tumours with downregulated miRNA-219 [88].

Table 1 miRNAs as biomarkers in pancreatic cancer ("= high mainly in early lesions)

\begin{tabular}{|c|c|c|c|c|c|c|}
\hline miRNA & Analysis Technique & Normal Pancreatic Tissues & Pancreatitis & PC & Cell lines & Reference \\
\hline$-20 a,-29 c 96,-141$ & Microarray & High & N/A & Low & N/A & {$[78]$} \\
\hline$-10 a,-10 b,-204,-372$ & Microarray & Low & N/A & High & N/A & {$[82]$} \\
\hline$-93,-133 a,-203,-205,-210,-224$ & Microarray & Low & N/A & High & High & {$[60]$} \\
\hline$-27 a$ & Microarray & Low & $\mathrm{N} / \mathrm{A}$ & High & N/A & {$[78]$} \\
\hline$-221,-222$ & Microarray, qRT-PCR & Low & N/A & High & High & {$[60,79]$} \\
\hline$-216,-217$ & Microarray & Very high & N/A & Very low & Very low & {$[60,78]$} \\
\hline \multirow[t]{2}{*}{$-200 a$} & Microarray, TaqMan low density array, qRT-PCR & Low & N/A & High & N/A & {$[78,81]$} \\
\hline & Microarray & High & & Low & & {$[60]$} \\
\hline$-196 a$ & Microarray, qRT-PCR & Absent & Absent & High & High & {$[60,78,79]$} \\
\hline$-15 b,-95,-186,-190,-200 b$ & qRT-PCR & Low & $\mathrm{N} / \mathrm{A}$ & High & N/A & {$[79]$} \\
\hline$-146 a$ & Microarray & Low & N/A & High & N/A & {$[78,82]$} \\
\hline$-143,-145,-150$ & Microarray & Low & High & High & Absent & {$[60]$} \\
\hline$-141,-148 a,-200 b,-200 c,-375$ & Microarray, TaqMan low density array, qRT-PCR & Low & N/A & $\mathrm{N} / \mathrm{A}$ & High & {$[80]$} \\
\hline$-139,-142,-345$ & qRT-PCR & Low & N/A & Low & $\mathrm{N} / \mathrm{a}$ & {$[76]$} \\
\hline$-100,-125 b-1,-212,-301,-424$ & qRT-PCR & Low & $\mathrm{N} / \mathrm{A}$ & High & $\mathrm{N} / \mathrm{a}$ & {$[76]$} \\
\hline-21 & Microarray, TaqMan low density array, qRT-PCR & Low & $\mathrm{N} / \mathrm{A}$ & High “ & High & {$[77,78,80,81]$} \\
\hline-155 & qRT-PCR & Low & N/A & High " & N/A & {$[77]$} \\
\hline-205 & qRT-PCR & Low & N/A & High " & N/A & {$[81]$} \\
\hline-375 & Microarray & High & Low & Low & Absent & {$[60]$} \\
\hline
\end{tabular}


Table 2 miRNAs as prognostic factors and the associated targets and survival status in pancreatic cancer

\begin{tabular}{lllll}
\hline miRNA & Expression in Pancreatic Cancer compared to normal tissue & Survival Status & Targets & Reference \\
\hline$-10 \mathrm{~b}$ & Upregulated & Poor Survival & TIP30 & [94, 95] \\
-21 & Upregulated & Worse Survival & PTEN, PDCD4, IL-6R,CDK6 & {$[85-87]$} \\
$-34 a$ & Upregulated & Better Survival & NOTCH, BCL2, CDK6 & [96-98] \\
-155 & Upregulated & Poor Survival & TP53INP & [99, 100] \\
- let-7 Family & Downregulated & Poor Survival & KRAS, HRAS, TRIM71 & [101, 102] \\
-200 Family & Downregulated & Better Survival & E-cadherin, ZEB & [91, 96, 103] \\
-216 & Downregulated & Poor Survival & ROCK1 & {$[104,105]$} \\
\hline
\end{tabular}

Furthermore, miRNAs could play a prolific role in the prediction of chemoresistance and responsiveness to different therapeutic approaches. For example, several markers indicate the degree of responsiveness, where miRNA-320c is a prognostic factor for gemcitabine clinical response prediction [89]. Moreover, postsurgery survival rates were higher in patients with increased levels of miRNA-200c (MST $=42$ months, 5-year survival rate $=33.5 \%$ ) than the lower miRNA-200c expressing individuals (MST $=19$ months, 5-year survival rate $=11.2 \%$ ). This observation correlated with low invasiveness of cells after the upregulation of miRNA-200c following in vitro experiments [90].

Irregular expression of miRNA was found in the development of a gemcitabine-resistant cell line. miRNA200b, miRNA-200c, let-7b, let-7c, let-7d and let-7e were downregulated in gemcitabine-resistant cells [91]. Similarly, miRNA-33a is also downregulated in gemcitabineresistant cells, and upon the restoration of normal levels, gemcitabine sensitivity was restored in the MIA-PaCa2 PC cell line [92]. Increased levels of miRNA-320c in gemcitabine-resistant cells suggests incorporation through regulation of SWI/SNF Related Matrix Associated Actin Dependent Regulator Of Chromatin Subfamily C Member 1 (SMARCC1), as benefits from the gemcitabine regimen were only found among the patients expressing SMARCC1. miRNA-205 was used in combination with gemcitabine as a chemosensitiser through decreased production of caveolin-1 and Ki-67 [93]. Orthotopic pancreatic mice were implanted with either lenti-hsamiRNA205 treated MIA PaCa-2R cells, or lenti-hsamiRNAScramble treated MIA PaCa-2R cells. Following intravenous delivery of GEM-conjugated polymeric micelles thrice weekly for two weeks at a concentration of $40 \mathrm{mg} / \mathrm{kg}$, it was observed that in the lentihsamiRNA205 treated cells there was a significant reduction in tumour growth. These mice bore tumours with average volumes of $77.83 \pm 21 \mathrm{~mm}$, compared to mice implanted with lenti-hsamiRNAScramble treated cells, which exhibited tumours of volumes of $172.85 \pm$ $17 \mathrm{~mm}$.

\section{Conclusions}

Due to the aggressive nature of PC and the lack of biomarkers, miRNAs represent a promising tool to help in the development of prediction, managing, and treating agents to improve low survival rates. The therapeutic potential of miRNAs can be implicated after investigating downstream regulatory mechanisms observed among different molecular pathways, as some can play a tumour suppressive role and others are oncomiRNAs. The restoration of these miRNAs levels to that of healthy tissue could therefore be beneficial in maintaining the endogenous anti-tumour regulatory mechanisms.

However, large-scale clinical studies need to be explored to establish clinical relevance of the collected data. To date, one clinical trial is ongoing studying miRNA-25 as a diagnostic tool in PC (NCT03432624) [106]. Variations in results among studies arise from using pancreatic specimens, which contain heterogenous cell populations. These cell types include the ductal, acinar, and islet cells, along with other inflammatory, fibroblastic components that will accompany the tumour development. Prediction of target genes of different miRNAs could be considered the major drawback of assigning miRNA in large scale applications, as the predictive algorithms give an enormous number of targets for a single miRNA. Attention should be given to the miRNA's mechanism of action, as more innovative methods will be required to validate the predicted targets.

RNAs are gaining momentum as therapy options. MRX34, for example, is a miRNA-34 mimic encapsulated within a lipid-based vessel known as NOV40. MRX34 was utilised in a multicentre phase I clinical trial (2013) for the treatment of patients with primary liver cancer, melanoma, lymphoma, small cell lung cancer, multiple myeloma or renal cell carcinoma. By June 2016, 99 patients were recruited onto the trial with HCC, NSCLC or pancreatic cancers. Following completion of the trial, 3 patients achieved prolonged confirmed partial responses. Moreover, 14 patients presented with stable disease (median duration- 136 days) [107]. An example of an FDA approved RNAi based therapy by Alnylam Pharmaceuticals is 
Onpattro $^{\text {tux }}$ for the treatment of polyneuropathy of hereditary transthyretin-mediated amyloidosis in adults. Onpattro $^{\mathrm{Tw}}$ contains patisaran, which comprises a siRNA conjugated with a lipid complex. The drug's mechanism of action results in binding with the TTR protein. The reduction in TTR protein levels in the liver results in a drop in amyloid deposits. The FDA approval of Onpattro ${ }^{\mathrm{Tm}}$ in August 2018 was the result of a successful Phase III clinical trial dubbed APOLLO. The trial had 225 patients enrolled, 148 of which received Onpattro $^{\text {th }}$ once every three weeks $(0.3 \mathrm{mg} / \mathrm{kg}$ body weight), while the remaining patients received a placebo drug. Patients receiving Onpattro ${ }^{\mathrm{Tu}}$ displayed improvements, with $51 \%$ of patients exhibiting an improved quality of life (measured using the Norfolk Quality of Life Diabetic Neuropathy (QoL-DN)), as opposed to only $10 \%$ in the placebo control [108].

MiRNAs hold potential as innovative gene therapies but success is heavily reliant on an efficient delivery vector $[109,110]$. If indeed miRNAs are to be used in pancreatic cancer, the delivery systems must transport the cargo to the destination site, not evoke an immune response and not have prohibitive production costs so that wide-spread adoption of the these nanotherapies can be realised.

\begin{abstract}
Abbreviations
BRCA2: Breast Cancer A2; CDKN2A: Cyclin-dependent Kinase; DM: Diabetes Mellitus; DNA: Deoxyribonucleic acid; elF4E: Eukaryotic Initiation Factor 4E; ERK: Extracellular Signal-regulated Kinase; FNA: Fine Needle Aspiration; GAP: GTPase Activating Protein; GTP: Guanosine Triphosphate; K-RAS: Kirsten Rat Sarcoma; LDH: Lactate Dehydrogenase; MAPK: Mitogen-activated Protein Kinase; miRNA: micro Ribonucleic acid; mRNA: messenger Ribonucleic acid; NE: Norepinephrine; oncomiR: Ongogenic micro Ribonucleic acid; PanIN: Pancreatic Intraepithelial Neoplasia; PC: Pancreatic Cancer; PDGFRb: Platelet-derived Growth Factor Receptor b; PI3K: Phosphoinositide3-kinase; RISC: RNA-induced silencing complex; RNA: Ribonucleic acid; SMAD: Mothers Against Decapentaplegic; SMARCC1: Chromatin Subfamily C Member 1; TGF $\beta$ : Transforming Growth Factor $\beta$; T $\beta R I I$ : Threonic Kinase Receptor II; UTR: Untranslated Region
\end{abstract}

\section{Acknowledgements}

Not Applicable.

\section{Authors' contributions}

HM was the lead PI and refined the manuscript. AD, EM and GC drafted the manuscript. AD and EM produced all the figures. All authors read and approved the final manuscript.

\section{Funding}

No funding to declare.

\section{Availability of data and materials}

Not Applicable.

\section{Ethics approval and consent to participate} Not Applicable.

\section{Consent for publication}

Not Applicable.

\section{Competing interests}

The authors declare that they have no competing interests.

\section{Author details}

'School of Pharmacy, Queen's University Belfast, 97 Lisburn Road, Northern Ireland BT9 7BL, UK. ${ }^{2}$ Gastrointestinal Stem Cell Biology Laboratory, Wellcome Trust Centre for Human Genetics, University of Oxford, Oxford OX3 7BN, UK. ${ }^{3}$ Genome Sciences Centre, British Columbia Cancer Agency, Vancouver, British Columbia V5Z 1L3, Canada. ${ }^{4}$ Department of Pathology and Laboratory Medicine, University of British Columbia, Vancouver V6T 2B5, Canada.

Received: 27 March 2019 Accepted: 24 October 2019

Published online: 21 November 2019

\section{References}

1. https://www.who.int/en/news-room/fact-sheets/detail/cancer.

2. "Pancreatic cancer statistics / Cancer Research UK." [Online]. Available: http:// www.cancerresearchuk.org/health-professional/cancer-statistics/statistics-bycancer-type/pancreatic-cancer. [Accessed: 06-Jan-2017].

3. Costa-Silva B, Aiello NM, Ocean AJ, Singh S, Zhang H, Thakur BK, et al. Pancreatic cancer exosomes initiate pre-metastatic niche formation in the liver. Nat Cell Biol. 2015;17(6):816-26.

4. Paiella S, Sandini M, Gianotti L, Butturini G, Salvia R, Bassi C. The prognostic impact of Para-aortic lymph node metastasis in pancreatic cancer: A systematic review and meta-analysis. Eur J Surg Oncol [Internet] 2016 May; 42(5):616-624. Available from: https://linkinghub.elsevier.com/retrieve/pii/ S0748798316000974

5. Li Z, Shang H, Zhang X, Zhang H, Bao J, Hao C. Surgical treatment for locally advanced pancreatic cancer localized in the pancreatic body and tail (report of 11 cases). Int J Clin Exp Med [Internet]. 2015;8(3):4676-4681. Available from: http://www.ncbi.nlm.nih.gov/pubmed/26064401.

6. Yachida S, Jones S, Bozic I, Antal T, Leary R, Fu B, et al. Distant metastasis occurs late during the genetic evolution of pancreatic cancer. Nature. 2010; 467(7319):1114-7.

7. Evans J, Chapple A, Salisbury H, Corrie P, Ziebland S. 'It can't be very important because it comes and goes'-patients' accounts of intermittent symptoms preceding a pancreatic cancer diagnosis: A qualitative study. BMJ Open. 2014;4(2):6-8.

8. Muniraj T, Chari ST. Diabetes and pancreatic cancer. Minerva Gastroenterol Dietol [Internet]. 2012 Dec;58(4):331-345. Available from: http://www.ncbi. nlm.nih.gov/pubmed/23207610.

9. Wang L, Bai Y-Y, Yang Y, Hu F, Wang Y, Yu Z, et al. Diabetes mellitus stimulates pancreatic cancer growth and epithelial-mesenchymal transition-mediated metastasis via a p38 MAPK pathway. Oncotarget. 2016;7(25):38539-50.

10. Javeed N, Sagar G, Dutta SK, Smyrk TC, Lau JS, Bhattacharya S, et al. Pancreatic cancer-derived exosomes cause paraneoplastic $\beta$-cell dysfunction. Clin Cancer Res. 2015;21(7):1722-33.

11. De Braud F, Cascinu S, Gatta G. Cancer of pancreas. Crit Rev Oncol Hematol. 2004;50(2):147-55.

12. Jones S, Zhang X, Parsons DW, Lin JC-H, Leary RJ, Angenendt P, et al. Core Signaling Pathways in Human Pancreatic Cancers Revealed by Global Genomic Analyses. Science (80- ). 2008 Sep;321(5897):1801 LP - 1801806.

13. Rozenbium E, Schutte M, Goggins M, Hahn SA, Panzer S, Zahurak M, et al. Tumor-suppressive Pathways in Pancreatic Carcinoma. Cancer Res. 1997; 57(9):1731-4

14. Mutations K, Ductal P. Pancreatic Ductal. 1994:145(6):1547-8.

15. Khan MA, Azim S, Zubair H, Bhardwaj A, Patel G, Khushman M, et al. Molecular drivers of Pancreatic Cancer pathogenesis: looking inward to move forward. Int J Mol Sci. 2017;18(4):779.

16. Maitra A. H. Hruban R. Pancreatic Cancer. Cancer Res. 2008;3:1-30.

17. Hingorani SR, Tuveson DA. Ras redux: rethinking how and where Ras acts. Curr Opin Genet Dev. 2003;13(1):6-13.

18. Jonckheere N, Vasseur R, Van Seuningen I. The cornerstone K-RAS mutation in pancreatic adenocarcinoma: from cell signaling network, target genes, biological processes to therapeutic targeting. Crit Rev Oncol Hematol. 2017;111:7-19.

19. Collins MA, Bednar F, Zhang Y, Brisset J, Galbán S, Galbán CJ, et al. Oncogenic Kras is required for both the initiation and maintenance of pancreatic cancer in mice. J Clin Invest. 2012;122(2):639-53.

20. Ying H, Kimmelman AC, Lyssiotis CA, Hua S, Chu GC, Fletcher-sananikone E, et al. Oncogenic Kras maintains Pancreatic tumors through regulation of anabolic glucose metabolism. Cell. 2010;149(3):656-70. 
21. Singh A, Greninger P, Rhodes D, Koopman L, Violette S, Bardeesy N, et al. A gene expression signature associated with 'K-Ras addiction' reveals regulators of EMT and tumor cell survival. Cancer Cell [Internet]. 2009 Jun 2;15(6):489-500. Available from: http://www.ncbi.nlm.nih.gov/ pubmed/19477428.

22. Bernard Weinstein I. Addiction to oncogenes: the Achilles heal of Cancer: DISCOVER: all subjects. S CIENCE ' S COMPASS. 2002;297(July):64-5.

23. Collins MA, Brisset J, Zhang Y, Bednar F, Pierre J, Galba S, et al. Metastatic Pancreatic Cancer Is Dependent on Oncogenic Kras in Mice. PLos One. 2012;7(12):e49707.

24. Nan X, Tamgüney TM, Collisson EA, Lin L-J, Pitt C, Galeas J, et al. Ras-GTP dimers activate the mitogen-activated protein kinase (MAPK) pathway. Proc Natl Acad Sci. 2015;112(26):7996-8001.

25. Roy SK, Srivastava RK, Shankar S. Inhibition of PI3K / AKT and MAPK / ERK pathways causes activation of FOXO transcription factor, leading to cell cycle arrest and apoptosis in pancreatic cancer. J Mol Signal. 2010;5:10.

26. Boucher MJ, Morisset J, Vachon PH, Reed JC, Lainé J, Rivard N. MEKJERK signaling pathway regulates the expression of $\mathrm{BCl}-2, \mathrm{BCl}-\mathrm{XL}$, and $\mathrm{MCl}-1$ and promotes survival of human pancreatic cancer cells. J Cell Biochem. 2000; 79(3):355-69.

27. Taniuchi K, Furihata M, Hanazaki K, Iwasaki S, Tanaka K, Shimizu T, et al. Peroxiredoxin 1 promotes pancreatic cancer cell invasion by modulating p38 MAPK activity. Pancreas. 2015;44(2):331-40.

28. Handra-luca A, Lesty C, Hammel P, Sauvanet A, Rebours V, Martin A, et al. Biological and Prognostic Relevance of Mitogen-Activated Protein Kinases in Pancreatic Adenocarcinoma. Pancreas. 2012;41(3):416-21.

29. Zhong Y, Naito Y, Cope L, Naranjo-Suarez S, Saunders T, Hong SM, et al. Functional p38 MAPK identified by biomarker profiling of pancreatic cancer restrains growth through JNK inhibition and correlates with improved survival. Clin Cancer Res. 2014;20(23):6200-11.

30. Huang X, Wang H, Yuan Z, Huang J, Zheng Q. Norepinephrine stimulates pancreatic cancer cell proliferation, migration and invasion via betaadrenergic receptor-dependent activation of P38/MAPK pathway. Hepatogastroenterology. 2012 May;59(115):889-93.

31. Ding XZ, Adrian TE. MEK/ERK-mediated proliferation is negatively regulated by p38 MAP kinase in the human pancreatic cancer cell line, PANC-1. Biochem Biophys Res Commun. 2001;282(2):447-53.

32. Cuadrado A, Nebreda AR. Mechanisms and functions of p38 MAPK signalling. Biochem J. 2010;429(3):403-17.

33. Schutte M, Hruban RH, Geradts J, Maynard R, Hilgers W, Rabindran SK, et al. Abrogation of the Rb/p16 Tumor-suppressive Pathway in Virtually All Pancreatic Carcinomas. Cancer Res. 1997:57(15):3126-30.

34. Ouelle DE, Zindy F, Ashmun RA, Sherr CJ. Alternative reading frames of the INK4a tumor suppressor gene encode two unrelated proteins capable of inducing cell cycle arrest. Cell. 1995;83(6):993-1000.

35. Bertoli C, Skotheim JM, De Bruin RAM, Street G, de Bruin RAM. Control of cell cycle transcription during G1 and S phases. Nat Rev Mol Cell Biol. 2015; 14(8):518-28.

36. Vogelstein B, Lane D, Levine AJ. Surfing the p53 network. Nature. 2000; 408(6810):307-10.

37. Makohon-Moore A, lacobuzio-Donahue CA. Pancreatic cancer biology and genetics from an evolutionary perspective. Nat Rev Cancer. 2016;16(9):553-65.

38. Redston MS, Caldas C, Seymour AB, Hruban RH, da Costa L, Yeo CJ, et al. p53 Mutations in Pancreatic Carcinoma and Evidence of Common Involvement of Homocopolymer Tracts in DNA Microdeletions. Cancer Res. 1994;54(11):3025-33.

39. Marcel V, Catez F, Diaz JJ. P53, a translational regulator: contribution to its tumour-suppressor activity. Oncogene. 2015;34(44):5513-23.

40. Herman JM, Crane CH, lacobuzio-Donahue C, Abrams RA. Pancreatic Cancer. In: Clinical Radiation Oncology [Internet]. Elsevier; 2016. p. 934-959.e6. Available from: https://linkinghub.elsevier.com/retrieve/pii/B978032324 0987000484

41. Siegel PM, Massagué J. Cytostatic and apoptotic actions of TGF- $\beta$ in homeostasis and cancer. Nat Rev Cancer. 2003 Nov;3(11):807-20.

42. Macias MJ, Martin-malpartida P, Massague J. Structural determinants of Smad function in TGF- b signaling. Trends Biochem Sci. 2015;40(6):296-308.

43. Budi EH, Duan D, Derynck R. Transforming growth factor- $b$ receptors and Smads : regulatory complexity and functional versatility. Trends Cell Biol. 2017;27(9):658-72.

44. Oshima M, Okano K, Muraki S, Haba R, Maeba T, Suzuki Y, et al. Immunohistochemically Detected Expression of 3 Major Genes (CDKN2A) p16, TP53, and SMAD4/DPC4) Strongly Predicts Survival in Patients With Resectable Pancreatic Cancer. Ann Surg. 2013;258(2).

45. Schmiedel JM, Klemm SL, Zheng Y, Sahay A, Blüthgen N, Marks DS, van Oudenaarden A. Gene expression. MicroRNA control of protein expression noise. Science. 2015;348(6230):128-32.

46. Mulholland EJ, Dunne N, McCarthy HO. MicroRNA as Therapeutic Targets for Chronic Wound Healing. Mol Ther - Nucleic Acids [Internet]. 2017 Sep 15 [cited 2018 Jan 29];8:46-55. Available from: https://www.sciencedirect.com/ science/article/pii/S2162253117301865?via\%3Dihub

47. Saini HK, Griffiths-jones S. Enright AJ. Genomic analysis of human microRNA transcripts. 2007;104(45):1-6.

48. Filipowicz W, Bhattacharyya SN, Sonenberg N. Mechanisms of posttranscriptional regulation by microRNAs: are the answers in sight? 2008; 9(february).

49. Hill CG, Jabbari N, Matyunina L V, Mcdonald JF. Functional and Evolutionary Significance of Human MicroRNA Seed Region Mutations. PLoS One. 2014; 9(12):e115241.

50. Dueck A, Ziegler C, Eichner A, Berezikov E, Meister G. microRNAs associated with the different human Argonaute proteins. Nucleic Acids Res [Internet]. 2012;40(19):9850-62. Available from: http://www.ncbi.nlm.nih.gov/ pubmed/22844086.

51. Ambros $V$, Chen $X$. The regulation of genes and genomes by small RNAs. Development. 2007;134(9):1635-41.

52. Meister $G$, Landthaler M, Patkaniowska A, Dorsett $Y$, Teng G, Tuschl T. Human Argonaute2 mediates RNA cleavage targeted by miRNAs and siRNAs. Mol Cell. 2004;15(2):185-97.

53. Zhang J, Li S, Li L, Li M, Guo C, Yao J, et al. Exosome and Exosomal MicroRNA: trafficking, sorting, and function. Genomics Proteomics Bioinformatics [Internet] 2015 Feb;13(1):17-24. Available from: https:// linkinghub.elsevier.com/retrieve/pii/S167202291500011X

54. Wang X, Luo G, Zhang K, Cao J, Huang C, Jiang T, et al. Hypoxic tumorderived Exosomal miR-301a mediates M2 macrophage polarization via PTEN/PI3Ky to promote Pancreatic Cancer metastasis. Cancer Res [Internet]. 2018;78(16):4586-4598. Available from: http://www.ncbi.nlm.nih.gov/ pubmed/29880482.

55. Pang $W$, Su J, Wang $Y$, Feng $H$, Dai $X$, Yuan $Y$, et al. Pancreatic cancersecreted miR-155 implicates in the conversion from normal fibroblasts to cancer-associated fibroblasts. Cancer Sci [Internet]. 2015 Oct;106(10):13621369. Available from: http://www.ncbi.nlm.nih.gov/pubmed/26195069.

56. Wang $M$, Yu F, Ding H, Wang Y, Li P, Wang K. Emerging Function and Clinical Values of Exosomal MicroRNAs in Cancer. Mol Ther - Nucleic Acids [Internet]. 2019 Jun;16:791-804. Available from: https://linkinghub.elsevier. com/retrieve/pii/S2162253119301209

57. Zhang B, Pan X, Cobb GP, Anderson TA. microRNAs as oncogenes and tumor suppressors. Dev Biol [Internet]. 2007 Feb;302(1):1-12. Available from: https://linkinghub.elsevier.com/retrieve/pii/S0012160606010967

58. Iorio M V, Croce CM. MicroRNA dysregulation in cancer: diagnostics, monitoring and therapeutics. A comprehensive review. EMBO Mol Med [Internet]. 2012 Mar;4(3):143-159. Available from: http://www.ncbi.nlm.nih. gov/pubmed/22351564.

59. Lu J, Getz G, Miska EA, Varez-Saavedra E, Lamb J, Peck D, et al. MicroRNA expression profiles classify human cancers. Nature. 2005;435(7043):834-8.

60. Szafranska AE, Davison TS, John J, Cannon T, Sipos B, Maghnouj A, et al. MicroRNA expression alterations are linked to tumorigenesis and nonneoplasticprocesses in pancreatic ductal adenocarcinoma. Oncogene. 2007; 26(30):4442-52.

61. Moody L, He H, Pan Y-X, Chen H. Methods and novel technology for microRNA quantification in colorectal cancer screening. Clin Epigenetics. 2017;9(1):119.

62. Yonemori K, Seki N, Idichi T, Kurahara H, Osako Y, Koshizuka K, et al. The microRNA expression signature of pancreatic ductal adenocarcinoma by RNA sequencing: anti-tumour functions of the microRNA-216 cluster. Oncotarget [Internet]. 2017 Sep 19;8(41):70097-70115. Available from: http:// www.ncbi.nlm.nih.gov/pubmed/29050264.

63. Mitchell PS, Parkin RK, Kroh EM, Fritz BR, Wyman SK, Pogosova-Agadjanyan EL, et al. Circulating microRNAs as stable blood-based markers for cancer detection. Proc Natl Acad Sci U S A. 2008 Jul;105(30):10513-8.

64. Wang H, Peng R, Wang J, Qin Z, Xue L. Circulating microRNAs as potential cancer biomarkers: the advantage and disadvantage. Clin epigenetics [Internet]. 2018;10:59. Available from: http://www.ncbi.nlm.nih.gov/ pubmed/29713393. 
65. Rawlings-Goss RA, Campbell MC, Tishkoff SA. Global population-specific variation in miRNA associated with cancer risk and clinical biomarkers. BMC Med Genomics [Internet]. 2014 Aug 28;7:53. Available from: http://www. ncbi.nlm.nih.gov/pubmed/25169894.

66. Crnogorac-Jurcevic T, Efthimiou E, Capelli P, Blaveri E. Baron a, Terris B, et al. gene expression profiles of pancreatic cancer and stromal desmoplasia. Oncogene. 2001;20(50):7437-46.

67. Humeau M, Torrisani J, Cordelier P. MiRNA in clinical practice: Pancreatic cancer. Clin Biochem. 2013;46(10-11):933-6.

68. Słotwiński R, Lech G, Słotwińska SM. MicroRNAs in pancreatic cancer diagnosis and therapy. Cent J Immunol [Internet]. 2018;43(3):314-324. Available from: http://www.ncbi.nlm.nih.gov/pubmed/30588176.

69. Abue M, Yokoyama M, Shibuya R, Tamai K, Yamaguchi K, Sato I, et al. Circulating miR-483-3p and miR-21 is highly expressed in plasma of pancreatic cancer. Int J Oncol [Internet]. 2015;46(2):539-47. Available from: http://www.ncbi.nlm.nih.gov/pubmed/25384963.

70. Wray CJ, Ahmad SA, Matthews JB, Lowy AM. Surgery for pancreatic cancer: recent controversies and current practice. Gastroenterology. 2005;128(6):1626-41.

71. Hong TH, Park IY, Tanaka K, Inoue Y, Kusunoki M, Boland C. MicroRNA expression profiling of diagnostic needle aspirates from surgical pancreatic cancer specimens. Ann Surg Treat Res. 2014;87(6):290.

72. Ballehaninna UK, Chamberlain RS. Serum CA 19-9 as a Biomarker for Pancreatic Cancer-A Comprehensive Review. Indian J Surg Oncol [Internet]. 2011;2(2):88-100. Available from: http://www.ncbi.n/m.nih.gov/pubmed/226 93400.

73. Winter JM, Yeo CJ, Brody JR. Diagnostic, Prognostic, and Predictive Biomarkers in Pancreatic. Cancer. May 2012;2013:15-22.

74. Saito $Y$, Jones PA. Epigenetic Activation of Tumor Suppressor MicroRNAs in Human Cancer Cells. Cell Cycle. 2006;5(19):2220-2.

75. Li Y, Sarkar FH. MicroRNA targeted therapeutic approach for pancreatic cancer. Int J Biol Sci. 2016;12(3):326-37.

76. Eun JL, Gusev Y, Jiang J, Nuovo GJ, Lerner MR, Frankel WL, et al. Expression profiling identifies microRNA signature in pancreatic cancer. Int J Cancer. 2007;120(5):1046-54

77. Habbe N, Koorstra JBM, Mendell JT, Offerhaus GJ, Ji KR, Feldmann G, et al. MicroRNA miR-155 is a biomarker of early pancreatic neoplasia. Cancer Biol Ther. 2009;8(4):340-6.

78. Hong TH, Park IY. MicroRNA expression profiling of diagnostic needle aspirates from surgical pancreatic cancer specimens. Ann Surg Treat Res. 2014;87(6):290-7.

79. Zhang $Y$, Li M, Wang H, Fisher WE, Lin PH, Yao Q, et al. Profiling of 95 MicroRNAs in pancreatic cancer cell lines and surgical specimens by real-time PCR analysis. World J Surg. 2009;33(4):698-709.

80. Mees ST, Schleicher C, Mardin WA, Senninger N, Colombo-Benkmann M, Haier J. Analyzing miRNAs in ductal adenocarcinomas of the pancreas. J Surg Res. 2011;169(2):241-6.

81. du Rieu MC, Torrisani J, Selves J, Al Saati T, Souque A, Dufresne M, et al. MicroRNA-21 Is Induced Early in Pancreatic Ductal Adenocarcinoma Precursor Lesions. Clin Chem. 2010;56:603-12.

82. Nakata K, Ohuchida K, Mizumoto K, Kayashima T, Ikenaga N, Sakai H, et al. MicroRNA-10b is overexpressed in pancreatic cancer, promotes its invasiveness, and correlates with a poor prognosis. Surgery. 2011;150(5): 916-22.

83. Namkung J, Kwon W, Choi Y, Yi SG, Han S, Kang MJ, et al. Molecular subtypes of pancreatic cancer based on miRNA expression profiles have independent prognostic value. J Gastroenterol Hepatol. 2015;31:n/a-n/a.

84. Wu P, Taubert H. Elevated expression of microRNAs 155, 203, 210 and 222 in pancreatic tumors is associated with poorer survival. Int J Cancer. 2009.

85. Giovannetti E, Funel N, Peters GJ, Del Chiaro M, Erozenci LA, Vasile E, et al. MicroRNA-21 in Pancreatic Cancer: correlation with clinical outcome and pharmacologic aspects underlying its role in the modulation of gemcitabine activity. Cancer Res [Internet] 2010;70(11):4528-4538. Available from: http://cancerres.aacrjournals.org/lookup/doi/10.1158/0008-54 72.CAN-09-4467

86. Asangani IA, Rasheed SAK, Nikolova DA, Leupold JH, Colburn NH, Post S, et al. MicroRNA-21 (miR-21) post-transcriptionally downregulates tumor suppressor Pdcd4 and stimulates invasion, intravasation and metastasis in colorectal cancer. Oncogene [Internet]. 2008;27(15):2128-36. Available from: http://www.ncbi.nlm.nih.gov/pubmed/17968323.

87. Guo S, Fesler A, Wang H, Ju J. microRNA based prognostic biomarkers in pancreatic Cancer. Biomark Res [Internet]. 2018;6(1):18. Available from: https://biomarkerres.biomedcentral.com/articles/10.1186/s40364-0180131-1

88. Bloomston M, Frankel WL, Petrocca F, Volinia S, Alder H, Hagan JP, et al. MicroRNA expression patterns to differentiate pancreatic adenocarcinoma from normal pancreas and chronic pancreatitis. Jama. 2007;297(17):1901-8.

89. Iwagami $Y$, Eguchi $H$, Nagano H, Akita H, Hama N, Wada H, et al. miR-320c regulates gemcitabine-resistance in pancreatic cancer via SMARCC1. Br J Cancer. 2013;109(2):502-11.

90. Yu J, Ohuchida K, Mizumoto K, Sato N, Kayashima T, Fujita H, et al. MicroRNA, hsa-miR-200c, is an independent prognostic factor in pancreatic cancer and its upregulation inhibits pancreatic cancer invasion but increases cell proliferation. Mol Cancer. 2010;28;9:169.

91. Li Y, VandenBoom TG, Kong D, Wang Z, Ali S, Philip PA, et al. Up-regulation of miR-200 and let-7 by natural agents leads to the reversal of epithelial-tomesenchymal transition in gemcitabine-resistant pancreatic cancer cells. Cancer Res. 2009 Aug;69(16):6704-12.

92. Liang C, Wang Z, Li YY, Yu BH, Zhang F, Li HY. miR-33a suppresses the nuclear translocation of $\beta$-catenin to enhance gemcitabine sensitivity in human pancreatic cancer cells. Tumor Biol. 2015;36(12):9395-403.

93. Chaudhary AK, Mondal G, Kumar V, Kattel K, Mahato RI. Chemosensitization and inhibition of pancreatic cancer stem cell proliferation by overexpression of microRNA-205. Cancer Lett. 2017;402(Supplement C):1-8.

94. Ouyang H, Gore J, Deitz S, Korc M. microRNA-10b enhances pancreatic cancer cell invasion by suppressing TIP30 expression and promoting EGF and TGF- $\beta$ actions. Oncogene [Internet]. 2014;33(38):4664-4674. Available from: http://www.nature.com/articles/onc2013405

95. Preis M, Gardner TB, Gordon SR, Pipas JM, Mackenzie TA, Klein EE, et al. MicroRNA-10b expression correlates with response to Neoadjuvant therapy and survival in Pancreatic Ductal adenocarcinoma. Clin Cancer Res. 2011; 17(17):5812-21 Available from: http://clincancerres.aacrjournals.org/cgi/doi/1 0.1158/1078-0432.CCR-11-0695.

96. Iliopoulos D, Drakaki A. MicroRNA-gene signaling pathways in pancreatic cancer. Biomed J [Internet]. 2013;36(5):200. Available from: http://biomedj. cgu.edu.tw/pdfs/2013/36/5/images/BiomedJ_2013_36_5_200_119690.pdf

97. Kong YW, Ferland-McCollough D, Jackson TJ, Bushell M. microRNAs in cancer management. Lancet Oncol [Internet]. 2012;13(6):e249-e258. Available from: https://linkinghub.elsevier.com/retrieve/pii/S1470204512700736

98. Ohuchida K, Mizumoto K, Kayashima T, Fujita H, Moriyama T, Ohtsuka T, et al. MicroRNA expression as a predictive marker for gemcitabine response after surgical resection of Pancreatic Cancer. Ann Surg Oncol. 2011;18(8):2381-7 Available from: http://www.springerlink.com/index/1 0.1245/s10434-011-1602-x.

99. Khan MA, Zubair H, Srivastava SK, Singh S, Singh AP. Insights into the role of microRNAs in Pancreatic Cancer pathogenesis: potential for diagnosis, prognosis, and therapy. Adv Exp Med biol [Internet]. 2015;889:71-87. Available from: http://www.ncbi.nlm.nih.gov/pubmed/26658997.

100. Mikamori M, Yamada D, Eguchi H, Hasegawa S, Kishimoto T, Tomimaru Y, et al. MicroRNA-155 controls exosome synthesis and promotes gemcitabine resistance in Pancreatic Ductal adenocarcinoma. Sci rep [Internet]. 2017;7: 42339. Available from: http://www.ncbi.nlm.nih.gov/pubmed/28198398.

101. Schultz NA, Andersen KK, Roslind A, Willenbrock H, Wøjdemann M, Johansen JS. Prognostic MicroRNAs in Cancer tissue from patients operated for Pancreatic Cancer-five MicroRNAs in a prognostic index. World J Surg. 2012;36(11):2699-707 Available from: http://link.springer.com/10.1007/s0026 8-012-1705-y.

102. Pai $P$, Rachagani $S$, Are C, Batra SK. Prospects of miRNA-based therapy for pancreatic cancer. Curr Drug Targets [Internet]. 2013;14(10):1101-9. Available from: http://www.ncbi.nlm.nih.gov/pubmed/23834151.

103. Paik WH, Song BJ, Kim HW, Kim HR, Hwang J-H. MicroRNA-200C as a Prognostic Biomarker for Pancreatic Cancer. Korean J Gastroenterol [Internet]. 2015;66(4):215. Available from: https://synapse.koreamed.org/DOlx php?id=10.4166/kjg.2015.66.4.215

104. Liu Y-A, Zhang Y, Zheng Z, Li K, Wu X-H, Du Q-G, et al. MicroRNA-216b reduces growth, migration and invasion of pancreatic ductal adenocarcinoma cells by directly targeting $\rho$-associated coiled-coil containing protein kinase 1. Oncol Lett [Internet]. 2018;15(5):6745-51. Available from: http://www.ncbi.n/m.nih.gov/pubmed/29616134.

105. Yi J, Li S, Wang C, Cao N, Qu H, Cheng C, et al. Potential applications of polyphenols on main ncRNAs regulations as novel therapeutic strategy for cancer. Biomed Pharmacother [Internet]. 2019;113:108703. Available from: https://linkinghub.elsevier.com/retrieve/pii/S0753332219300010 
106. https://clinicaltrials.gov/ct2/show/NCT03432624.

107. Beg MS, Brenner A, Sachdev J, Ejadi S, Borad M, Kang Y-K, et al. Abstract C43: Safety, tolerability, and clinical activity of MRX34, the first-in-class liposomal miR-34 mimic, in patients with advanced solid tumors. Mol Cancer Ther [Internet]. 2015;14(12 Supplement 2):C43-C43. Available from: http://mct. aacrjournals.org/lookup/doi/10.1158/1535-7163.TARG-15-C43

108. https://www.drugdevelopment-technology.com/projects/onpattro-forhereditary-transthyretin-mediated-amyloidosis/.

109. Cole G, Ali AA, McErlean E, Mulholland EJ, Short A, McCrudden CM, et al. DNA vaccination via RALA nanoparticles in a microneedle delivery system induces a potent immune response against the endogenous prostate cancer stem cell antigen. Acta Biomater [Internet]. 2019 Jul; Available from: https://linkinghub.elsevier.com/retrieve/pii/S1742706119304830

110. McCarthy HO, McCaffrey J, McCrudden CM, Zholobenko A, Ali AA, McBride JW, et al. Development and characterization of self-assembling

nanoparticles using a bio-inspired amphipathic peptide for gene delivery. J Control Release [lnternet]. 2014;189:141-9. Available from: http://www.ncbi. nlm.nih.gov/pubmed/24995949.

\section{Publisher's Note}

Springer Nature remains neutral with regard to jurisdictional claims in published maps and institutional affiliations.

Ready to submit your research? Choose BMC and benefit from:

- fast, convenient online submission

- thorough peer review by experienced researchers in your field

- rapid publication on acceptance

- support for research data, including large and complex data types

- gold Open Access which fosters wider collaboration and increased citations

- maximum visibility for your research: over $100 \mathrm{M}$ website views per year

At BMC, research is always in progress.

Learn more biomedcentral.com/submissions 